\section{BMJ Open Respiratory Research}

\title{
Experiences of nurses caring for respiratory patients during the first wave of the COVID-19 pandemic: an online survey study
}

\author{
Nicola J Roberts (D) , ${ }^{1}$ Carol A Kelly (D) , ${ }^{2}$ Kate A Lippiett, ${ }^{3}$ Emma Ray, ${ }^{4}$ \\ Lindsay Welch ${ }^{3}$
}

To cite: Roberts NJ, Kelly CA, Lippiett KA, et al. Experiences of nurses caring for respiratory patients during the first wave of the COVID-19 pandemic: an online survey study. BMJ Open Resp Res 2021;8:e000987. doi:10.1136/ bmjresp-2021-000987

Received 10 May 2021 Accepted 27 June 2021
Check for updates

\section{(C) Author(s) (or their} employer(s)) 2021. Re-use permitted under CC BY-NC. No commercial re-use. See rights and permissions. Published by BMJ.

${ }^{1}$ School of Health and Life Sciences, Glasgow Caledonian University, Glasgow, UK ${ }^{2}$ Respiratory Research Centre, Edge Hill University Faculty of Health and Social Care, Ormskirk, UK

${ }^{3}$ Faculty of Environmental and Life Sciences, University of Southampton, Southampton, UK

${ }^{4}$ Sovereign Health Network, Fareham, UK

Correspondence to Dr Nicola J Roberts; nicola.roberts@gcu.ac.uk

\section{ABSTRACT}

Background Nurses have been at the forefront of the pandemic response, involved in extensive coordination of services, screening, vaccination and front-line work in respiratory, emergency and intensive care environments. The nature of this work is often intense and stressprovoking with an inevitable psychological impact on nurses and all healthcare workers. This study focused on nurses working in respiratory areas with the aim of identifying and characterising the self-reported issues that exacerbated or alleviated their concerns during the first wave of the COVID-19 pandemic.

Methods An online survey was developed consisting of 90 questions using a mixture of open-ended and closed questions. Participant demographic data were also collected (age, gender, ethnicity, number of years qualified, details of long-term health conditions, geographical location, nursing background/role and home life). The online survey was disseminated via social media and professional respiratory societies (British Thoracic Society, Primary Care Respiratory Society, Association of Respiratory Nurse Specialists) over a 3-week period in May 2020 and the survey closed on 1 June 2020.

Results The study highlights the experiences of nurses caring for respiratory patients during the first wave of the pandemic in early 2020 . Concerns were expressed over the working environment, the supply and availability of adequate protective personal equipment, the quality of care individuals were able to deliver, and the impact on mental health to nurses and their families. A high number provided freetext comments around their worries and concerns about the impact on their household; these included bringing the virus home, the effect on family members worrying about them, mental health and the impact of changing working patterns, and managing with children. Although both formal and informal support were available, there were inconsistencies in provision, highlighting the importance of nursing leadership and management in ensuring equity of access to services. Conclusions Support for staff is essential both throughout the pandemic and afterwards, and it is important that preparation of individuals regarding building resilience is recognised. It is also clear that psychological support and services for nurses and the wider healthcare team need to be available and quickly convened in the event of similar major incidents, either global or local.

\section{Key messages}

This study reports the experiences of nurses working with respiratory patients during the first wave of the pandemic

- Nurse participants reported significant impact on themselves and their families as they supported respiratory patients during the pandemic.

- It is important that we learn from our experiences during the first wave of the pandemic and make sure we support nurses and other healthcare professionals in any future pandemics.

\section{INTRODUCTION}

The COVID-19 pandemic has had an unprecedented and long-lasting impact on health systems, individuals and healthcare professionals, with a consequent impact on society, the full extent of which has not yet been revealed. $^{1-3}$

The response to the pandemic and the initial crisis faced by health services needed a coordinated and sustained approach to reinforce resource availability and provide access to appropriate clinical care. This required many staff to be retrained and redeployed to key clinical areas to provide the necessary support through skilled clinical resource. ${ }^{4}$ In the UK, as the number of patients hospitalised with COVID-19 increased during the first quarter of 2020, a concurrent rise in sickness levels among healthcare professionals was reported, with 1 in 10 nursing and midwifery absences, ${ }^{5}$ although it is uncertain if these were attributed to infection, fatigue or isolation. Bird $e t a t^{6}$ found that nurses and those working in respiratory care settings had higher rates of infection compared with other professional groups and settings; not surprising as most patients suspected of COVID-19 would be assessed initially by respiratory teams, with 
nurses most likely to have the longest and most interactions with patients.

Nurses are the largest workforce within the healthcare system, integral to the management of a pandemic, delivering direct patient care and coordinating services. ${ }^{78}$ This often includes performing aerosol generating procedures (AGPs), which may place staff at high risk of exposure to the virus, particularly in the absence of protective personal equipment (PPE), as AGP can produce water droplets which can then be inhaled. Bronchoscopy, sputum induction, provision of high-flow nasal oxygen and manual ventilation are examples of AGP. ${ }^{9}$ Nurses have been at the forefront of the pandemic response therefore not only in terms of numbers but also in their extensive involvement in coordination of services, screening, vaccination and front-line work in respiratory, emergency and intensive care environments. The nature of this work is often intense and stress-provoking with an inevitable psychological impact on nurses and all healthcare workers. ${ }^{10}$

Maben and Bridges ${ }^{11}$ suggest that contributing factors to high stress levels during the first wave of the pandemic included changing protocols and ways of working, increased exposure to end-of-life experiences, redeployment, concerns around personal and family health, long shifts, limited access to COVID-19 testing, and lack of PPE. These personal and professional issues often conflict with healthcare professionals' perceived professional and moral duty to provide an essential, potentially life-saving service.

The psychological impact on those working with patients during the COVID-19 pandemic and its consequent toll on the mental health of the workforce has been recognised. ${ }^{1012}{ }^{13}$ Healthcare professionals have experienced negative mental health outcomes including depression, anxiety, insomnia and stress. ${ }^{14}$ A recent UK survey on the mental health of the nursing workforce during the pandemic ${ }^{15}$ found that over $80 \%$ of participating nursing staff experienced increased levels of stress and over $30 \%$ stated that their current mental health and well-being were affected. Previously reported findings from our survey (also in the UK) found $21 \%$ of a sample of 255 nurses experienced moderate to severe or severe symptoms of anxiety, with similar levels of depression. ${ }^{16}$ Previous studies relating to the Ebola crisis ${ }^{17} 18$ also report that the risk to the mental health of those working in pandemic situations is high, with symptoms appearing during, but more often after, the crisis is over. Working in healthcare during the COVID-19 pandemic therefore may be associated with both short-lasting and long-lasting psychological effects. ${ }^{19}$ Experiences from previous pandemics confirm front-line healthcare professionals may develop poor mental health as a consequence, including formal mental health disorders such as post-traumatic stress disorder (PTSD) ${ }^{17}$ and moral injury. ${ }^{20}$ Moral injury refers to the moral distress caused by the powerlessness of healthcare professionals to meet patients' needs in a situation of high demand and constrained resources, and it has been linked with the development of suicidal thoughts, depression, anxiety, flashbacks or PTSD. ${ }^{21}$

It is paramount that the importance of the impact on mental health and psychological well-being on all parts of the healthcare workforce is identified, characterised and addressed. In this study, we focus on nurses working in respiratory areas with the aim of identifying and characterising the self-reported issues that exacerbated or alleviated their concerns. We aim to identify areas that individuals, organisations and policy makers can target which may help to alleviate the psychological consequences of the pandemic on nurses and the wider healthcare workforce.

\section{METHODS}

\section{Design of the survey tool}

The survey tool was devised by a panel of clinical and non-clinical researchers, including respiratory nurses. The survey consisted of 90 questions using a mixture of open-ended and closed questions, to allow both qualitative as well as quantitative data to be collected. Three validated clinical tools were also included in the survey: the Resilience Scale, ${ }^{22}$ the General Anxiety Disorder Assessment (GAD-7) to capture levels of anxiety ${ }^{23}$ and the Patient Health Questionnaire (PHQ-9) ${ }^{24}$ to assess levels of depression (results reported elsewhere ${ }^{16}$ ).

Data were collected on participant characteristics such as age, gender, ethnicity, number of years qualified and details of long-term health conditions (that may have had an impact on nursing practice during the pandemic). Data were also collected on UK geographical location, nursing background/role and home life.

The survey was piloted with respiratory nurses from local networks and members of the Association of Respiratory Nurse Specialists to evaluate readability and highlight where improvements could be made. From this, minor changes were made to enhance ease of understanding.

The online survey was designed using REDCap. The survey link was disseminated via social media (Twitter). In addition, UK respiratory societies circulated the survey link to their members (British Thoracic Society, Primary Care Respiratory Society, Association of Respiratory Nurse Specialists). Potential participants were invited to complete the survey (an estimated 15-20 min in duration). The survey link was retweeted regularly over a 3-week period in May 2020 and the survey closed on 1 June 2020.

\section{Data collection}

The minimum number for the study was pragmatically estimated to be approximately 150 participants. The survey sampled registered nurses in the UK working with respiratory and/or patients with COVID-19 in primary, community and secondary care settings. We included those who had been fast-tracked and registered early because of the pandemic, those who had come out of 
retirement or had been redeployed to work in a clinical area managing patients with COVID-19.

\section{Data analysis}

This paper centres on the survey questions, focusing on mental health and mental health support. Our previous paper ${ }^{16}$ focused on anxiety, depression and resilience scores. Survey data were entered into SPSS (V.25.0) for analysis. Descriptive statistical analysis and univariate inferential testing (Mann-Whitney, Kruskal-Wallis) were undertaken for the survey responses when appropriate.

Content analysis was applied to the free-text answers in the surveys to identify and characterise the phenomena of interest. An inductive approach was applied whereby recurring words, terms or phrases were identified, and content was coded, combined and then categorised into overarching themes. ${ }^{25}$ Survey responses were reviewed for individual comments and read repeatedly by the research team to enhance rigour.

\section{Patient and public involvement}

This study used nursing staff as participants and therefore it was not appropriate to involve patients or the public in the design, or conduct, or reporting or dissemination plans for this study.

Consent was inferred from completion of the survey; participants were not required to complete a consent form. Information about the study was available to participants on the social media link and researcher contact details were available for any questions or queries. Mental health advice and signposting were included at the end of the survey in case any distress was inadvertently caused. The panel devising the survey tool included nurses who had discussed at length each question, taking into account the need to minimise burden to participants at an already stressful time.

\section{FINDINGS}

\section{Demographics}

In total, 255 responses were received for the survey, predominately from women $(89 \%)$, with the majority aged over 35 (79\%) (table 1). Just under 95\% (94.9\%, 242 of 255) of the respondents classed themselves as white and only a small sample of other ethnic groups completed the survey. Most were living with their partner and children $(43.1 \%, 110$ of 255) or with their partner alone (25.9\%, 66 of 255). Just over 20\% (20.8\%, 53 of 255) of the participants reported having a long-term condition.

Of the participants, 9\% (23 of 255) reported that they were in an at-risk (vulnerable) group. The sample also included at-risk vulnerable participants, who may have changed role because of their shielding status, for example, carrying out telephone consultations.

Of the participants, $58 \%$ (147 of 255) stated that they usually worked in an acute setting. A similar proportion
Table 1 Demographics of survey respondents $(\mathrm{N}=255)$

\section{Frequency (\%)}

\begin{tabular}{ll}
\hline $\begin{array}{ll}\text { Age (years), mean (SD) } \\
\text { Age (years) }\end{array}$ & $45.1(9.77)$ \\
\hline $18-35$ & $53(20.8)$ \\
\hline $36-50$ & $104(40.8)$ \\
\hline $50+$ & $98(38.4)$ \\
\hline Gender & \\
\hline Male & $28(11.0)$ \\
\hline Female & $226(88.6)$ \\
\hline Prefer not to say & $1(0.4)$ \\
\hline Ethnicity & \\
\hline White & $242(94.9)$ \\
\hline Asian & $7(2.7)$ \\
\hline All other ethnic groups & $6(2.4)$ \\
\hline
\end{tabular}

Years qualified

\begin{tabular}{|c|c|}
\hline$<20$ & $109(42.7)$ \\
\hline$>20$ & $146(57.3)$ \\
\hline \multicolumn{2}{|l|}{ UK region } \\
\hline Scotland & $23(9.0)$ \\
\hline Northern Ireland & $7(2.7)$ \\
\hline Wales & $11(4.3)$ \\
\hline England (excluding London) & $200(78.4)$ \\
\hline Greater London & $\begin{array}{l}14 \text { (5.5) } \\
\text { (England: North East 11, North } \\
\text { West 30, Yorkshire and Humber } \\
35 \text {, West Midlands 16, East } \\
\text { Midlands 28, South West 22, } \\
\text { South East 43, East of England } \\
\text { 15) }\end{array}$ \\
\hline \multicolumn{2}{|l|}{ Usual clinical setting } \\
\hline Acute & $147(57.6)$ \\
\hline Community & $45(17.6)$ \\
\hline Primary care & 27 (10.6) \\
\hline Other & $15(5.9)$ \\
\hline \multicolumn{2}{|c|}{ Change of role during the COVID-19 pandemic } \\
\hline Yes & $146(57.3)$ \\
\hline No & $72(28.2)$ \\
\hline \multicolumn{2}{|l|}{$\begin{array}{l}\text { Undertaking aerosol } \\
\text { generating procedures }\end{array}$} \\
\hline Yes & $124(48.6)$ \\
\hline No & $96(37.6)$ \\
\hline \multicolumn{2}{|l|}{ Living arrangements } \\
\hline Alone & $11(4.3)$ \\
\hline With partner/spouse & $66(25.9)$ \\
\hline $\begin{array}{l}\text { With partner/spouse and } \\
\text { children }\end{array}$ & $110(43.1)$ \\
\hline Single parent with children & $13(5.1)$ \\
\hline With extended family & $9(3.5)$ \\
\hline
\end{tabular}

Continued 


\begin{tabular}{cl}
\hline Table 1 & Continued \\
\hline & \multicolumn{1}{c}{ Frequency (\%) } \\
\hline Yes & $24(13.3)$ \\
No & $175(68.8)$ \\
Do you have a long-term condition? & $201(78.8)$ \\
No & $53(20.8)$ \\
Yes & (cardiac 8; diabetes 7; asthma \\
& 29, other 9) \\
\hline
\end{tabular}

$(57.3 \%, 146$ of 255$)$ had changed their role due to the pandemic, while $48.6 \%$ (124 of 255) stated they were undertaking AGPs.

\section{Concerns over working environment}

Participants were asked to choose multiple options (all that applied) on their concerns over their working environment. The majority of respondents $(65.5 \%, 167$ of 255) were worried that their working environment placed them at increased risk of passing on the virus to relatives or friends. Just under $50 \%$ were worried about contracting the virus themselves $(45.5 \%, 116$ of 255$)$ or becoming exhausted $(29.8 \%, 76$ of 255$)$. Just over $28 \%$ (72 of 255) were concerned about PPE and 27.8\% (71 of 255) were worried about long-term stress. Just under $15 \%$ (38 of 255) chose the 'other' option, with a total of 55 comments included as free text. Many respondents (10 of 55) added additional concerns around PPE and working conditions, despite this being an option in the original question:

Poor PPE. I don't believe a thin apron that hardly covers me, a surgical mask and normal gloves hold enough protection for me as many colleagues have been infected. I wish we could wear the respirator/fit mask style masks. (ID255)

Lack of connection between nurse managers who do not work clinically making safer decisions based on PPE availability and the feeling of dispensability felt by most frontline/bedside staff. (ID1)

Again, despite this being an option in the question, concerns about infecting family were reiterated in the free-text box $(n=7)$. Worries about mental health and stress $(n=6)$ were mentioned. Participants poignantly described caring for people, many of whom would go on to die, and the consequent impact not just on themselves, but also on those they work with:

I'm worried that I along with many nurses will burn out and our mental health will be affected. The deaths that we are seeing have increased massively compared to what we are used to. (ID53)

I think the long hours and the extensive use of PPE is exhausting not only are we nursing these people but fundamentally becoming their family often the last people to see them alive, we know that many won't survive despite best efforts. The odds are against us and I worry that in many it will lead to some form of PTSD. (ID67)

Changes in the delivery of care and potentially poor delivery of compassionate quality care were highlighted $(\mathrm{n}=5)$.

Lack of compassion seen, lack of 1:1 care, feeling inadequate due to loss of power and influence, concern over the COVID patients and their support on discharge and follow up arrangements, concern for my 'old' role/service and whether it will return, trying to keep up with both areas of work. (ID77)

Others raised concerns about switching to telephone and video consultations, the challenges of a change of role, the difficulty of making complex clinical decisions through such media and the isolation incumbent on this form of consultation $(n=3)$.

lots of very difficult clinical decisions to make with tel/video consultation. Organising investigations for acute or high risk non- COVID related symptoms exhausting - sitting at the computer in isolation for 8+hrs a day. (ID177)

Others highlighted the stress of changing job roles $(n=5)$, isolation around homeworking $(n=5)$, and stepping up and taking on additional/managerial roles $(n=2)$.

I haven't worked in a ward environment since I left ICU [intensive care unit.] in 2000. I hadn't done a drug round since 1998 and had no experience of using the IT system around patient observations and administering drugs. There was an expectation that I would just pick this up whilst managing a CPAP unit, and managing staff sickness and anxieties. Along with ensuing adequate PPE was delivered, ensuring the redesigned CPAP ward had appropriate portering, linen, catering etc. (ID190)

\section{Worries or concerns about the impact of the clinical role on} the respondent's household

Respondents were asked to give free-text answers about their worries and concerns about the impact of their clinical role on their household (table 2). Out of the 255 respondents, 206 provided often extensive, free-text comments. As with the previous question, a significant number of respondents reported that they were worried about taking the virus home $(\mathrm{n}=110)$. Participants were often concerned about being asymptomatic carriers of the virus and described additional precautions they were taking. Participants emphasised that their family or household were worried about them working in their clinical role $(n=18)$. Many reported that family members were worried, particularly children who were concerned, asking parents if they were going to die: 
Table 2 Worries or concerns about the impact of your clinical role $(n=206)$

Worried about family/ bringing virus home $(n=110)$

"Being asymptomatic and passing virus onto family members who then become very poorly because of myself." (ID141)

"Added stress to myself impacts how I act at home. Worry that I will bring the virus home to my husband and children." (ID42)

"It affects them greatly as they worry about me going to work every day. One family member doesn't sleep well because of this. I worry about them this way but main worry is bringing it home. I couldn't forgive myself especially as a person I live with is 90 years old." (ID16)

"The risk of bringing COVID home is the major concern. I shower before I leave work, have different lunch box/cutlery for work. I stopped watching the news/updates \& regularly listening to the radio as it was too depressing \& stressful. Only had limited COVID internet/news input by choice." (ID32)

No concerns $(n=42) \quad$ "No concerns about my role having an impact, concerns/anxieties are more generalized to do with breakdown of social distancing, not seeing my family and generalized worry." (ID87)

"None at the moment. have already suffered from COVID." (ID111)

"None. I don't go out, bit sad about that. I do all my food shopping in the hospital shop." (ID248)

Family worried/family views about your role $(n=18)$

"Family are anxious and stressed, worried about me working in a dangerous environment. Risk of bringing virus home and infecting family. Stress of work impacting family time - unable to/too tired for homeschooling for example." (ID79)

"My children are worried about me catching the virus. I worry how they are coping. And the effect this is having on them emotionally." (ID32)

"They are worried about my risk and see how overwhelming the experience is even doing telephone calls." (ID177)

"I worry a great deal as my daughter is very anxious about me going to work. She asks if I will die or if she will die. This causes a great deal of upset in my household." (ID48)

Change in working hours/ "Change in working hours. Covering 8-8 7 days a week. Impacting on family life." (ID172)

covering other roles/ working environment $(n=12)$

"I have been working longer hours and more shifts and my children are missing not having me around as much. They are staying up late so they can see me after 13 hour shifts. Husband struggling to work from home and look after children as he is so busy, so he is really stressed." (ID191)

"Working overtime means less time at home. Also may have to move to an on call rota if surge arrives pretty good so far." (ID37)

"Uncertainty of duration of redeployment, reduced prospects of going back to old role (elective CPAP/NIV introduction is an AGP), social isolation from family." (ID103)

Stress/mental health $(n=9)$ "Emotional stress if anything- difficult conversations over the phone..." (ID178)

"Exhaustion and emotionally drained when getting home not able to switch off." (ID147)

"Feeling guilty that I am out working whilst they're stuck at home. Feeling that I am missing out on the quality time with my child whilst he's off school." (ID184)

"I am tired and stressed at times. I work such long hours I am home very late with little time to see them." (ID65)

Impact on homeschooling $(n=5)$

"I worry the children have 2 parents who are key workers and as teenagers are home alone. I worry that they are at a disadvantage with regards to home schooling compared to those with parents/carers at home. I am concerned that they may feel more isolated with no parents at home." (ID173)

"Not being around as much, not giving the home teaching that is required as they don't get teaching at the school care setting." (ID63)

"Lack of education while transitioning to secondary." (ID133)

"My children are consistently worried and unsure with what I do in my job role." (ID225)

"My children's schooling as not able to support home schooling as much as I would like." (ID242)

$\operatorname{PPE}(n=3)$

"My worries are not being enough protected as having inadequate PPE." (ID99)

"My main concern is not enough protection due to not adequate PPE." (ID98)

"Not having the correct PPE and passing it to my family members, there is a lot of different PPE guidance for every trust." (ID23)

Being ill alone/or both parents ill at the same time $(\mathrm{n}=2)$

"My only concern is catching CV19 and living alone." (ID28)

"That one or both of us become unwell and be unable to care for our children or pass on the virus to our children." (ID139)

Lack of childcare $(n=2)$

"Both been key workers with no child care support our clinical role has made it impossible to spent more than 1 day a week as a family because we are working opposite shifts to provide childcare." (ID80) "Children have to go to school, can't stay at home as much as l'd like them to." (ID162)

Bringing my worries and "Bringing my emotions and worries home." (ID53)

stress home $(n=2)$ "Bringing my stress home!" (ID150)

Miscellaneous $(n=1)$

"Yes, as people from BAME being affected more \& diabetic patients are considered as most vulnerable Our local risk assessment did not include these two criteria." (ID75)

AGP, aerosol generating procedure; BAME, Black, Asian and Minority Ethnic; CPAP, Continuous Positive Airway Pressure; NIV, Non Invasive Ventilation; PPE, protective personal equipment. 
I worry a great deal as my daughter is very anxious about me going to work. She asks if I will die or if she will die. This causes a great deal of upset in my household. (ID48)

Some discussed their worry about the impact of their work on their families and the consequences on their families' mental health. Only a small number reported personal stress and mental health issues $(n=9)$; most were more concerned about taking the virus home and the impact on other family members rather than themselves.

Several respondents reported changes in their working pattern, including an increase or change in working hours, stating that it had affected their family life $(n=12)$. Some described working longer hours and the additional impact on managing home-schooling for children:

I worry the children have 2 parents who are key workers and as teenagers are home alone. I worry that they are at a disadvantage with regards to home schooling compared to those with parents/carers at home. I am concerned that they may feel more isolated with no parents at home. (ID173)

I have been working longer hours and more shifts and my children are missing not having me around as much. They are staying up late so they can see me after 13-hour shifts. Husband struggling to work from home and look after children as he is so busy, so he is really stressed. (ID191)

Work-life pressure, including lack of support with childcare $(n=2)$ and concern about how they (as parents) may cope if they contract the virus $(n=2)$, was also noted.

A large group $(n=42)$ of participants reported no concerns or worries; for some this was a consequence of living alone, others had already had COVID-19 or had family members who were also on the front line. Some had changed behaviour to reduce the risk of contracting the virus.

\section{Provision of mental health services}

Of the respondents, $57 \%$ (145 of 255) provided free-text comments on this question. Many respondents said they had been provided with access to mental health services during the pandemic but did not report whether they had used them. Most responses detailed the services that they knew about and were available but had not necessarily accessed, such as self-referral to services, email support/signposting services, telephone support, counselling services, chaplaincy, huddles/hubs, occupational support and webinars. Most of the support resources available were not face-to-face. Participants also mentioned the availability of wobble rooms and well-being areas.

I have set up a WhatsApp group for my team who are redeployed to the ward for support and also I have made an unused room in my now empty clinic room into a 'wobble room' where the staff can rest and try and gather their thoughts. It has lots of tissues, soft music, coffee and love. (ID81)
A small number reported that they were uncertain about how to access provision and others $(n=7)$ were not aware of any current support services from their employers. One respondent reported that different facilities were available for doctors compared with nurses.

\section{Informal support networks}

Respondents were asked about informal support networks for themselves and colleagues that they set up, used or had access to during the peak of the pandemic. Of the respondents, $76 \%$ (194 of 255) provided free-text responses to this question (table 3). A small number had existing groups in place $(n=4)$; six respondents reported that daily phone calls, video or emails were in place. Most reported use of social media such as WhatsApp, Zoom or Teams for communicating $(n=78)$, with some using this method for lunch breaks or for catching up with redeployed staff. A large number had regular team meetings or briefings or informal chats $(n=16)$ or access to other resources such as daily chats or well-being or wobble rooms. Several respondents had buddy systems in place or were checking in or providing support to others $(n=18)$. Fifty-eight respondents reported that they had not set up any informal networks or support groups.

\section{Additional support from management team}

Respondents were asked using a multiple-choice question what additional support has been given from their management team (all that applied). Respondents reported that they had a mixture of flexible working patterns $(32.5 \%, 83$ of 255$)$, emotional support $(29.4 \%$, 75 of 255$)$ and clear leadership (28.6\%, 73 of 255$)$. Freetext responses show that $4.7 \%$ (12 of 255) stated they had received support such as additional staff, support from manager and meeting updates. Some reported additional support $(n=12)$, with manager support and encouragement. However, a minority $(n=17)$ reported little or no support. This may be due to shift patterns or changes due to redeployment:

As I work out of hours, have very little contact with managers. (ID199)

Redeployment has caused some leadership confusion. (ID158)

\section{DISCUSSION}

This survey study set out to document the experiences of nurses caring for respiratory patients during the first wave of the pandemic with a focus on the mental health of nurses.

Of the sample surveyed, most participants had experienced a change in their usual role. Around half of the participants felt adequately prepared for the pandemic, although initial anxieties regarding PPE and safety were expressed. Nurses also reported concern over the emotional health of their household and not being able to meet these needs, particularly for those with children. Family support can be protective against stress; however, 
Table 3 Informal support networks $(n=194)$

Existing groups in place $(n=4)$ "I set up a group for the new people that started around the same time in ICU." (ID254)

"We have always had a good support network with messaging." (ID217)

None $(n=7)$

"Not really. We just talk to each other about difficult things/times." (ID16)

Daily video/phone calls/ emails $(n=6)$

"Daily phone calls to my team plus WhatsApp group." (ID92)

"I have set up a WhatsApp group for my team who are redeployed to the ward for support and also I have made an unused room in my now empty clinic room into a 'wobble room' where the staff can rest and try and gather their thoughts. It has lots of tissues, soft music, coffee and love." (ID81)

Safe spaces $(n=4) \quad$ "We have a wobble room on the ward where we can go if we feel stressed." (ID80)

"Using our ward day room as a 'NOVID room' to allow better social distancing \& promote wellbeing." (ID91)

Team meetings/ conversations/briefings $(n=16)$

"As a team we hold huddles to discuss how we are feeling. As a manager I have ensured we take walking breaks every day and have asked everyone to have at least two annual leave days each month to step away from work." (ID102)

"As the team leader I have spoken with the team individually and tried to address issues." (ID190) "We have a health check huddle at 11-1130. It allows a debrief and update. Support staff struggling with pts/relatives." (ID265)

"regular team meetings, huddles and team working." (ID87)

Social media: WhatsApp/ "Lots of WhatsApp groups and work does Microsoft teams for important stuff." (ID68)

SMS (short message service) "Support and wellbeing on TEAMS." (ID113)

message group/Teams $(n=78)$

"What's app group for those of us who were redeployed to the original covid ward. Private ward Facebook page (no information out on there, just messages of support) Emails, safety brief talks with team." (ID262)

"Zoom meeting/chat ensuring we stop for lunch \& a catch up." (ID130)

"Yes via google hangouts." (ID133)

"Social media page for staff in my area to communicate and express any concerns." (ID56) "Wellbeing closed Facebook group for staff." (ID42)

Providing support to others/ checking in with colleagues/ buddy system $(n=18)$

"We have two 'buddies' on the ward area we can chat with, but as a whole workplace we are supporting ourselves and talking, no support from seniors had come through." (ID23)

"I have provided my telephone number to a couple of nurses who have been struggling, one with anxiety about coming to work and the other who has lost a very close friend and colleague to Covid virus." (ID140)

"Just linked in with two colleagues all junior doctors were provided with a consultant mentor and although part of that team I was not allocated. Highlighted to general manager but not seen as a priority. Despite delivering majority of bad news over phone on frequent basis to relatives." (ID264) "Nothing formal just peer support." (ID197)

"We have a socially distanced glass of wine/gin on a Thursday evening - great to unwind and for morale." (ID43)

Psychological support/ volunteer support $(n=3)$

"We have an in house clinical psychologist for COPD patients. They have provided weekly videos about relaxation and mindfulness and offered confidential 1 to 1 sessions with all staff on the respiratory unit." (ID270)

"Yes we have a group that support our colleagues such as bereavement, volunteer works shopping and delivery of food." (ID59)

An additional 58 participants stated that 'no' they had not set up any informal groups.

COPD, Chronic Obstructive Pulmonary Disease; ICU, intensive care unit.

during a pandemic this has been shown to be a risk factor for psychological distress. ${ }^{26}$

While the majority had changed behaviour to accommodate working in a potentially infectious area, many still had concerns about catching the virus themselves or passing it on to their families and friends. This concern is substantiated as healthcare workers have been shown to be over seven times as likely to get severe COVID-19 compared with non-essential workers. ${ }^{27}$ In particular, the rate of positive COVID-19 tests in healthcare workers in respiratory wards, especially nurses in those areas, showed the highest positive rate compared with other medical specialties. ${ }^{6}$ This is possibly a result of most patients suspected of COVID-19 being referred initially to the respiratory areas for assessment and nurses spending more prolonged time with patients at more frequent intervals, including carrying out personal care such as washing patients.

Participants expressed concern regarding their own mental health, stating that they were physically exhausted and felt emotionally drained. A study of nurses' COVID-19 experiences of psychological health and safety in Canada demonstrated prevalence rates of suicide ideation two to three times higher in the nursing workforce than the national average. ${ }^{28}$ In our study, the majority of respondents were aware of available mental health services, but for many this was not accessed. This could be related to stigma associated with accessing such 
services or it may have been that resources were often remote and not available face-to-face. Additionally, it may have been that individuals did not recognise their own mental health needs or displayed a stoic and altruistic attitude towards their work. ${ }^{29}$ These healthcare professionals presented a strong professional identity over-riding most concerns about their own health. As a result, nurses often used their own personal networks and social media forums to access informal peer support or engage with initiatives such as wobble rooms. These are areas that provide psychological first aid to staff with an emotional space to strengthen solidarity and provide support. ${ }^{30}$ Informal support networks, including the use of social media, peer support and informal briefings, were regularly accessed during the pandemic by many participants. Many had additional psychological support, were providing buddy systems, and providing safe spaces as well as the use of social media to support peers and team members. Support from colleagues is particularly important for these stressful and emotionally demanding roles, and the role of social support, from work and personal friends, has been highlighted elsewhere. ${ }^{31} 32$ Opportunities for mentorship or 'buddying' with more experienced colleagues may be helpful, ${ }^{33}$ and although anecdotally signs of appreciation are gratefully received the 'hero narrative' has been criticised for inhibiting discussions regarding rights and boundaries and stripping responsibility from politicians. ${ }^{34}$

It was apparent however that there was inequity in the provision of bespoke COVID-19 psychological support services between organisations and to different staff groups. Throughout the pandemic, it has been increasingly recognised that access to mental health services and support will be fundamental to healthcare professionals' recovery and long-term well-being. It is recommended that support is stratified and that a variety of tiers are available which can be matched to individual needs. ${ }^{35}$ Accessible strategies that can be implemented to manage psychological distress have been also suggested, for example good sleep hygiene and maintenance of social support and relationships in and out of work. ${ }^{36}$

For such interventions to work, however, leadership and management support will be necessary. Less than a third of the nurses in this survey felt they had received additional support from their management team, and with some stating they had no support, including little or no contact with managers. But our study also revealed examples of good support mechanisms provided, although inconsistent. Consideration of the difficult circumstances that everyone was working under needs acknowledgement however, with managers and leaders needing to deal with change under pressure also. One of the key roles of leadership in the National Health Service (NHS) is providing psychological and mental health support, ${ }^{37}$ and managers need to be compassionate and to consider staff's personal circumstances. ${ }^{38}$ Policy recommendations at an organisational level are also needed to adequately support nurses, ${ }^{39}$ ensuring, where possible, organisational justice is embedded in the culture; this can include providing opportunities to manage workload, training and flexibility to create a positive environment which can protect against stress and burnout. ${ }^{40} \mathrm{WHO}$ has published guidelines to help alleviate the likelihood of developing psychological issues for healthcare workers during the pandemic. ${ }^{10}$

\section{Limitations}

The study was advertised through professional societies and through social media, which may have limited the sampling frame. However, it was important to make sure that NHS staff were not overburdened at this difficult time so social media was primarily used for this reason rather than recruiting through NHS routes. It is possible that we have missed some potential participants who do not use social media or were too stressed or busy to participate. This was a time-limited survey to ensure that we captured the experiences at the beginning of the pandemic. In order to mitigate this limitation, the survey has been repeated to understand the experiences of nurses at a different time of the pandemic. This survey was limited to nurses working in respiratory areas, which limited the sample size and response in comparison with other larger studies in the USA and Canada looking generally at nurses' experience during the pandemic.

\section{Summary, relevance to clinical practice and recommendations}

The findings from this study have highlighted the experiences of nurses caring for respiratory patients during the first wave of the pandemic. Concerns were expressed over the working environment, the supply and availability of adequate PPE, the quality of care individuals were able to deliver and the resultant moral injury suffered. An overwhelming fear was related to the spread of infection to families and friends and the impact of adjusting working patterns to respond to demand from clinical responsibilities. This highlights the need for social support mechanisms to be available to healthcare staff and their families if necessary. Additionally, participants acknowledged experiencing concern regarding their own mental health, and although both formal and informal support were available there were inconsistencies in provision, highlighting the importance of nursing leadership and management in ensuring equity of access to services.

Support for staff is essential both throughout the pandemic and afterwards and it is important that preparation of individuals regarding building resilience is recognised. It is also clear that psychological support and services for nurses and the wider healthcare team need to be available and quickly convened in the event of similar major incidents, either global or local.

Contributors All authors contributed to the design, analysis and writing of the study. 
Funding The authors have not declared a specific grant for this research from any funding agency in the public, commercial or not-for-profit sectors.

Competing interests The authors received support from the Association of Respiratory Nurse specialists for the article processing charges

Patient and public involvement Patients and/or the public were not involved in the design, or conduct, or reporting, or dissemination plans of this research.

Patient consent for publication Not required.

Ethics approval The study was approved by the School of Health and Life Sciences Committee at Glasgow Caledonian University (HLS/NCH/19/036).

Provenance and peer review Not commissioned; externally peer reviewed.

Data availability statement No data are available. Ethical approval was not sought to share the data outwith the research team.

Open access This is an open access article distributed in accordance with the Creative Commons Attribution Non Commercial (CC BY-NC 4.0) license, which permits others to distribute, remix, adapt, build upon this work non-commercially, and license their derivative works on different terms, provided the original work is properly cited, appropriate credit is given, any changes made indicated, and the use is non-commercial. See: http://creativecommons.org/licenses/by-nc/4.0/.

ORCID iDs

Nicola J Roberts http://orcid.org/0000-0002-7589-8113

Carol A Kelly http://orcid.org/0000-0002-9927-1382

\section{REFERENCES}

1 ONS. Coronavirus (COVID-19) - Office for National Statistics, 2020. Available: https://www.ons.gov.uk/peoplepopulationandcommunity/ healthandsocialcare/conditionsanddiseases [Accessed 14 Jan 2021].

2 Butler MJ, Barrientos RM. The impact of nutrition on COVID-19 susceptibility and long-term consequences. Brain Behav Immun 2020;87:53-4.

3 Fiorillo A, Gorwood P. The consequences of the COVID-19 pandemic on mental health and implications for clinical practice. Eur Psychiatry 2020;63:e32.

4 Willan J, King AJ, Jeffery K, et al. Challenges for NHS hospitals during covid-19 epidemic. BMJ 2020;368:m1117.

5 West D. One in 10 Hospital nurses absent due to coronavirus I news | health service Journal, 2020. Available: https://www.hsj.co.uk/ workforce/one-in-10-hospital-nurses-absent-due-to-coronavirus/ 7027394.article [Accessed 14 Jan 2021].

6 Bird P, Badhwar V, Fallon K, et al. High SARS-CoV-2 infection rates in respiratory staff nurses and correlation of COVID-19 symptom patterns with PCR positivity and relative viral loads. J Infect 2020;81:452-82.

7 Johnstone M-J, Turale S. Nurses' experiences of ethical preparedness for public health emergencies and healthcare disasters: a systematic review of qualitative evidence. Nurs Health Sci 2014;16:67-77.

8 Jackson D, Bradbury-Jones C, Baptiste D, et al. Life in the pandemic: some reflections on nursing in the context of COVID-19. J Clin Nurs 2020;29:2041-3.

9 Trust UHBNF. Aerosol generating procedures, 2020. Available: https://www.uhb.nhs.uk/coronavirus-staff/aerosol-generatingprocedures.htm [Accessed 26 Aug 2020].

10 WHO. Mental health and psychosocial considerations during the COVID-19 outbreak, 2020. Available: https://www.who.int/docs/ default-source/coronaviruse/mental-health-considerations.pdf? sfvrsn=6d3578af_2 [Accessed 26 Aug 2020].

11 Maben J, Bridges J. Covid-19: supporting nurses' psychological and mental health. J Clin Nurs 2020;29:2742-50.

12 Maben J, Bridges J. Covid-19: Supporting nurses' psychological and mental health. J Clin Nurs 2020;15307.

13 Greenberg N. Mental health of health-care workers in the COVID-19 era. Nat Rev Nephrol 2020;16:425-6.

14 Lai J, Ma S, Wang Y. Associated with mental health outcomes among health care workers JAMA network open. JAMA Netw Open 2020;3:203976.

15 Ford S. Exclusive: nursing times survey reveals negative impact of Covid-19 on nurse mental health | nursing times. Nurs. Times 2020 https://www.nursingtimes.net/news/mental-health/exclusive-surveyreveals-negative-impact-of-covid-19-on-nurse-mental-health-29-042020/

16 Roberts NJ, McAloney-Kocaman K, Lippiett K, et al. Levels of resilience, anxiety and depression in nurses working in respiratory clinical areas during the COVID pandemic. Respir Med 2021;176:106219.

17 Greenberg N, Wessely S, Wykes T. Potential mental health consequences for workers in the Ebola regions of West Africa-a lesson for all challenging environments. J Ment Health 2015;24:1-3.

18 Paladino L, Sharpe RP, Galwankar SC, et al. Reflections on the Ebola public health emergency of international concern, part 2: the unseen epidemic of posttraumatic stress among health-care personnel and survivors of the 2014-2016 Ebola outbreak. J Glob Infect Dis 2017:9:45-50.

19 Taegtmeyer Wingfield;. Healthcare workers and coronavirus: behind the stiff upper lip we are highly vulnerable, 2020. Available: https:// theconversation com/healthcare-workers-and-coronavirus-behindthe-stiff-upper-lip-we-are-highly-vulnerable-133864 [Accessed 14 Jan 2021].

20 Sheather J, Fidler H. Covid-19 has amplified moral distress in medicine. BMJ 2021;372:n28.

21 Williamson V, Murphy D, Stevelink SAM, et al. The impact of trauma exposure and moral injury on UK military veterans: a qualitative study. Eur J Psychotraumatol 2020;11:1704554.

22 Wagnild G. RS14 - Resilience Scale 14-items, 2009. Available: https://eprovide.mapi-trust.org/instruments/resilience-scale-14items [Accessed 2 Jul 2020].

23 Spitzer RL, Kroenke K, Williams JBW, et al. A brief measure for assessing generalized anxiety disorder: the GAD-7. Arch Intern Med 2006;166:1092-7.

24 Spitzer RL, Kroenke K, Williams JBW. Validation and utility of a selfreport version of PRIME-MD: the PHQ primary care study. J Am Med Assoc 1999;282:1737-44.

25 Chinn PL, Kramer MK. Knowledge development in nursing: theory and process. Elsevier Health Sciences 1999 https://onlinelibrary. wiley.com/doi/10.1111/j.1365-2648.2007.04569.x\#b8

26 Maunder RG, Lancee WJ, Balderson KE, et al. LongTerm psychological and occupational effects of providing Hospital healthcare during SARS outbreak. Emerg Infect Dis 2006;12:1924-32.

27 Mutambudzi M, Niedwiedz C, Macdonald EB, et al. Occupation and risk of severe COVID-19: prospective cohort study of 120075 UK Biobank participants. Occup Environ Med 2020;0:1-8.

28 Havaei F, Macphee M, Ma A. A provincial study of nurses' COVID-19 experiences of psychological health and safety in British Columbia 2020.

29 Missel M, Bernild C, Dagyaran I, et al. A stoic and altruistic orientation towards their work: a qualitative study of healthcare professionals' experiences of awaiting a COVID-19 test result. BMC Health Serv Res 2020;20:1031.

30 Rimmer A, Chatfield C. What organisations around the world are doing to help improve doctors' wellbeing. BMJ 2020;369:m1541.

$31 \mathrm{Hu} \mathrm{Z}$, Chen B. The status of psychological issues among frontline health workers confronting the coronavirus disease 2019 pandemic. Front Public Health 2020;8:265.

32 Teoh, Kinman G K. Looking after doctors' mental wellbeing during the covid-19 pandemic - The BMJ, 2020. Available: https://blogs. bmj.com/bmj/2020/03/26/looking-after-doctors-mental-wellbeingduring-the-covid-19-pandemic/ [Accessed 15 Jan 2021].

33 Guhde J. When orientation ends...supporting the new nurse who is struggling to succeed. J Nurses Staff Dev 2005;21:145-9.

34 Halberg N, Jensen PS, Larsen TS. We are not heroes-The flipside of the hero narrative amidst the COVID19-pandemic: a Danish Hospital ethnography. J Adv Nurs 2021;77:2429-36.

35 Tracy DK, Tarn M, Eldridge R, et al. What should be done to support the mental health of healthcare staff treating COVID-19 patients? $\mathrm{Br}$ $J$ Psychiatry 2020;217:537-9.

36 Heath C, Sommerfield A, von Ungern-Sternberg BS. Resilience strategies to manage psychological distress among healthcare workers during the COVID-19 pandemic: a narrative review. Anaesthesia 2020;75:1364-71.

37 Stanz L, Weber RJ. Leadership approaches to staff health and wellness during COVID-19 pandemic. Hosp Pharm 2020;001857872093658.

38 Vera San Juan N, Aceituno D, Djellouli N, et al. Mental health and well-being of healthcare workers during the COVID-19 pandemic in the UK: contrasting guidelines with experiences in practice. BJPsych Open 2021;7:e15.

39 Rosa WE, Schlak AE, Rushton $\mathrm{CH}$. A blueprint for leadership during COVID-19. Nurs Manage 2020;51:28-34.

40 Rama-Maceiras P, Jokinen J, Kranke P. Stress and burnout in anaesthesia: a real world problem? Curr Opin Anaesthesiol 2015;28:151-8 